\title{
Measurements of dynamic wind pressures on gable roofs - comparison with CSN EN 1991-1-4
}

\author{
Stanislav Pospíšil ${ }^{1, *}$, Michael Macháček ${ }^{1}$, Stanislav Hračov ${ }^{1}$, Sergey Kuznetsov ${ }^{1}$ and \\ Arsenii Trush $^{1}$ \\ ${ }^{1}$ ITAM AV ČR, v.v.i., Prosecká 76, Prague 9, 19000, Czech Republic
}

\begin{abstract}
The contribution is dealing with the wind tunnel measurements of dynamic pressures on the canopy roofs. It compares experimentally determined pressure coefficients $C_{p}$ with the values in ČSN EN 1991-1-4 and former code ČSN 730035 as well. The pressures are expressed by the dynamic values. Thus, the averaged values are presented together with the fluctuating part, which significantly contributes to the overall loading. The measurement is carried out at two roof models, two basic directions, and two turbulence intensities.
\end{abstract}

\section{Introduction}

Knowledge of wind pressures and the pressure coefficients on the building roofs is basic to the accurate wind-resistant design of structures. There has been much investigation of the wind characteristics on the gable roofs in different regions, see, [1], [2]. The magnitude and distribution of the wind pressures are analyzed in [3]. The wind tunnel tests are often indispensable for the designers, because the current codes sometimes do not give adequate values with respect to some zones at wind exposure. The extremely high local suctions may occur in the leading edges of longitudinal wall and windward roof, roof corners, and roof ridge under strong wind. The aspect ratio of building has a certain effect on the mean wind pressure coefficients, and there exist the effect relates to wind attack angle as well. Also the type of the exposure (terrain) is important. The paper [4] discusses the phenomenon that the suburban exposure produces lower wind loads than those experienced in the open country and compares the local pressures on low buildings with gable roof. Another paper, [5] analyses the wind pressure on gable roof buildings, through comparisons with existing results and relative wind load codes. In [6], the pressure spectral values are compared for both wind tunnel and full-scale measurement. The coherence of pressures was identical in full scale and wind tunnel in many cases and is better than that predicted in quasi-steady theory. In the papers [7, 8], the background for the Eurocode EN 1991-1-4 of the pressure coefficients is discussed. The reliability of the codification for wind loading is treated in paper [9].

\footnotetext{
* Corresponding author: pospisil@itam.cas.cz
} 
The present article is a preliminary study with emphasis on the understanding of wind pressure on gable roof buildings, through comparisons with existing related wind load codes. The wind tunnel measurements are used to compare pressure coefficients $C_{p}$ with the values in ČSN EN 1991-1-4 [10] and in expired code ČSN 730035 [11] which in some zones give very different results. The pressures are expressed by the averaged values together with the fluctuating part, which significantly contributes to the overall loading. The measurement is carried out at two aerodynamic models with different roof inclination for two basic directions in both smooth and turbulent flow.

\section{Measurement set-up}

\subsection{Model preparation}

Two models made of plexiglass with plane dimensions $b \times d=30 \times 30 \mathrm{~cm}$ and height $h=16 \mathrm{~cm}\left(\alpha=5^{\circ}\right)$, respectively, $h=30 \mathrm{~cm}\left(\alpha=45^{\circ}\right)$ were produced. The legend for the gable roof and the exposed zones according to [10] is shown in Fig. 1. Scheme of the model and the photograph of the manufactured scaled exposed to the wind pressures are shown in Fig. 2. The size of the model was chosen so as to avoid the possibility of the flow blockage in the wind tunnel. The ratio between the model area $A_{m}$ and the tunnel cross section $A_{t}$ is $A_{m} / A_{t}=2.5 \%$ and $3.7 \%$, respectively. Measurement of the pressure coefficient is thus not distorted; as the systematic error of $10 \%$ at the windward side of the model occurs when the blockage is higher than $5 \%$ while for the leeward side it is even less, see [3]. According to [4], the correction effect by blockage (calculated according for the model over the entire height of the tunnel) and used for the dimensions of the presented building model is only $6 \%$. It can therefore be assumed that for the measured case in which pressure is determined on the roof it is not necessary to consider a correction.
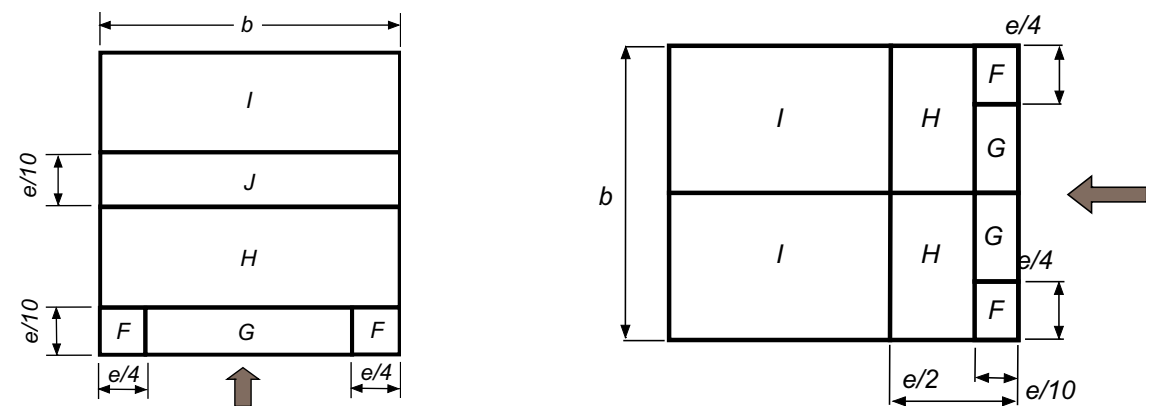

Fig. 1. Scheme of the pressure zones for the gable roof according to [10]. Left-wind direction $0^{\circ}$. Right-wind direction $90^{\circ}$. Dimension $e$ is the lower one from the values $b$ or $2 h$.

The examined object models were equipped with the pressure probes; small holes on the roof. Silicone tubing connected these probes with the dynamic pressure sensor type Honeywell DC002NDR5. This is a sensitive differential pressure gauge with a range of about $500 \mathrm{~Pa}$ and the sensitivity $5 \mathrm{~Pa}$ in the full range. The objects were placed in a smooth flow with very low turbulence intensity $I_{t}=1.4 \%$ and then to a turbulent stream with modelled atmospheric boundary layer with turbulence intensity $I_{t}=26 \%$. 

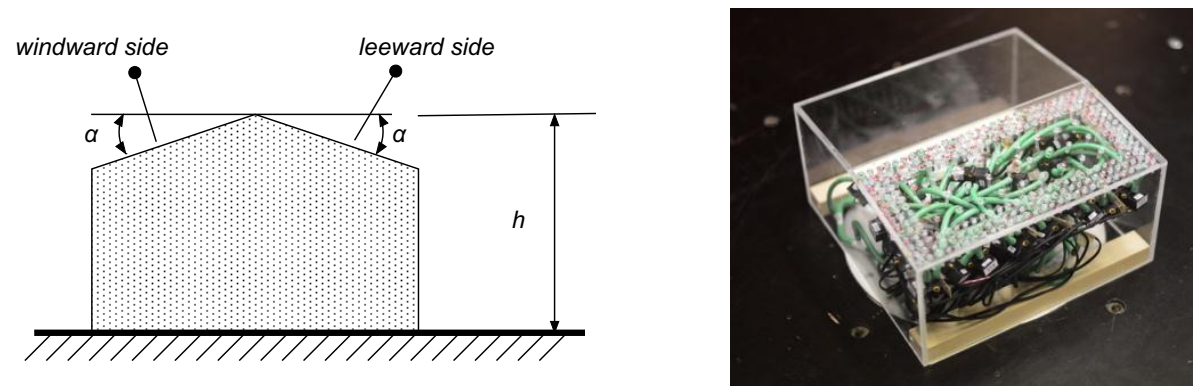

Fig. 2. Scheme of the gable roof and roof inclination. The photograph of the model with the pressure taps and sensors.

\subsection{Model testing}

The pressures at the smooth model gable roof were ascertained for five wind directions, i.e., the three main directions of $\theta=0^{\circ}, 90^{\circ}, 180^{\circ}$ and on the secondary incidence angles $\theta=45^{\circ}$ and $\theta=135^{\circ}$, which are not evaluated in this paper. The model was placed in the measuring part of the aerodynamic section of the tunnel, where the wind speed can be produced up to $50 \mathrm{~m} / \mathrm{s}$. Wind speed is measured by the Prandtl - Pitot tube in place of the undisturbed stream before the model, see photo in Fig. 3. The model was at first loaded with the speeds in the range of $10 \%-70 \%$ of the fan power, which is $3.0 \mathrm{~m} / \mathrm{s}$ to $20 \mathrm{~m} / \mathrm{s}$, in order to determine whether the pressure coefficient depends on the flow speed. Finally, the tests were carried out at a speed of about $16 \mathrm{~m} / \mathrm{s}$, i.e., in the part of the interval where the local pressures coefficients are independent of the wind speed. In other words, Reynolds number was in the range of $\mathrm{Re}=3.9 \times 10^{5}$ corresponding to the values in prototype scale. This value guarantees, see [3], the independence of the results at Re. Each partial measurement with 32 channels representing 32 spots on the roof surface took 30 seconds. This sampling time is sufficient with respect of the ergodicity and stationarity of the process.
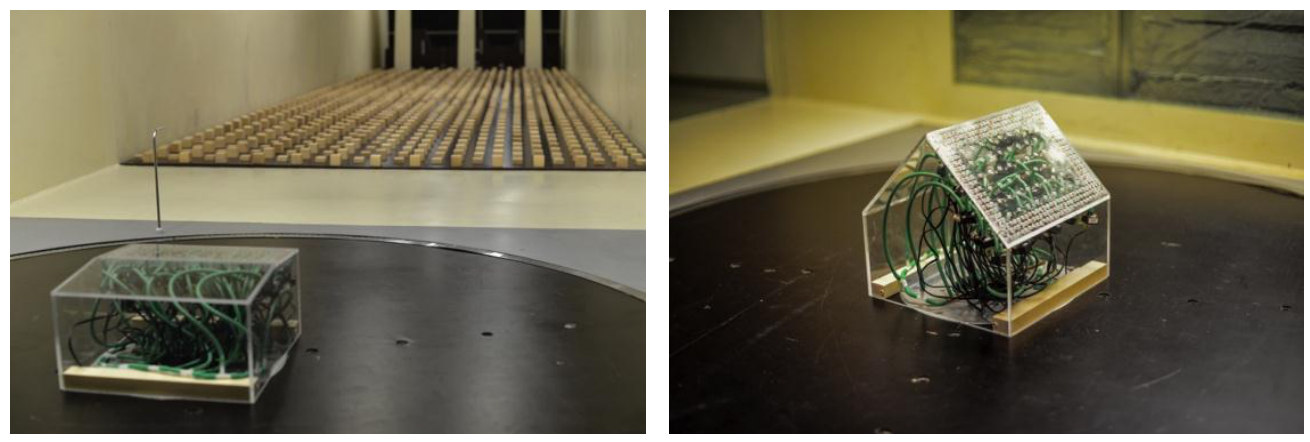

Fig. 3. Measured gable roof in the wind tunnel. The photograph is taken from the measurement in the turbulent atmospheric boundary layer.

Transfer of the results from the tunnel to the real measure is implemented through the pressure coefficient:

$$
C_{p}=2\left(p_{x}-p_{r}\right) / \rho V_{r}^{2}
$$

Value $p_{x}$ is pressure at the measuring points on the model; $p_{r}$ is static (barometric) pressure at a reference point, i.e., at the site of the free stream; $\rho$ is the density of air and $V_{r}$ is the mean wind speed at the reference location. Differential pressure is measured directly by a pressure transducer and represents the wind pressure at the sampling site. Pressure on the 
real building is then obtained by multiplying the pressure coefficient by the value of dynamic pressure $p_{d}=0.5 \rho V_{r}^{2}$. In the case of the turbulent flow, the terrain category IV was selected. The wind speed profile fits very well the profile given in [10]. The turbulence intensity in the test section is $I_{t}=26 \%$. The normalized spectral density of the wind speed, showing the energy distribution of the fluctuation component in the frequency domain corresponds to the Von Karmán spectrum utilized to describe the dynamic effect of the wind. This is seen in Fig. 5 below.
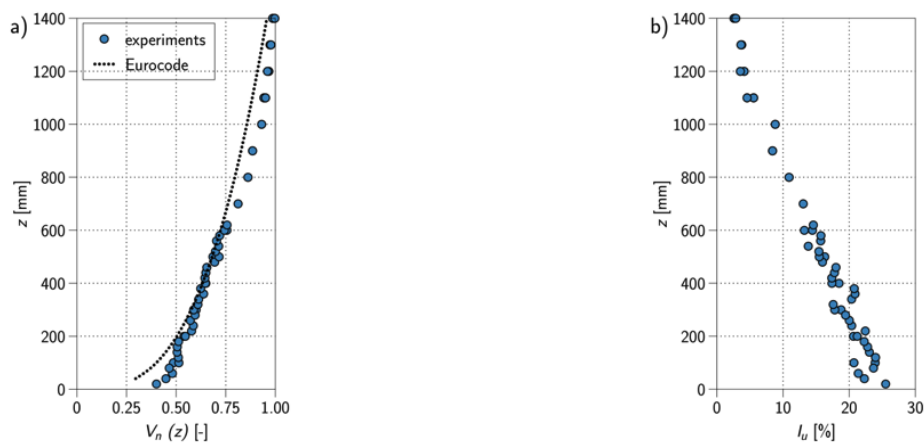

Fig. 4. a) Atmospheric boundary layer simulated in wind tunnel; b) turbulence intensity.

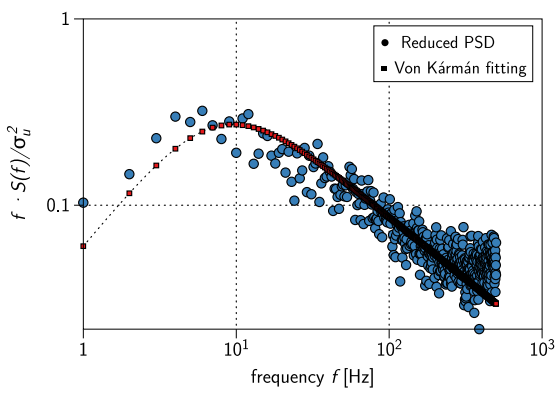

Fig. 5. Wind velocity power spectral density and the fitting to the theoretical values.

\section{Results and discussion}

The measurement results (non-dimensional pressure coefficients) are summarized in Fig. 613 and on Tables 1-2. The results are shown in the form of the maps of the local pressure coefficients over the roof plan. These values can be compared with the values in [10] as well as with the coefficients in the former Czechoslovak code [11]. Tables 1 and 2 give the average values of the coefficients and corresponding standard deviations (RMS) for each zone F, G, H, I and J as seen in Fig. 1. The methodology of division of the whole roof into the zones has been adopted for the [11] as well. For the evaluation of the data the authors selected relatively simple methodology expressed by the mean values pressure augmented by the standard deviation. The latter represents the fluctuating pressures which naturally create the additional loading at the roof. Thus, for the comparison with the codes, the effective maximum values of suction or pressure were selected. They are highlighted by red colour in Tables 1-2. Alike, the nearest values from the both codes are selected and accented. 

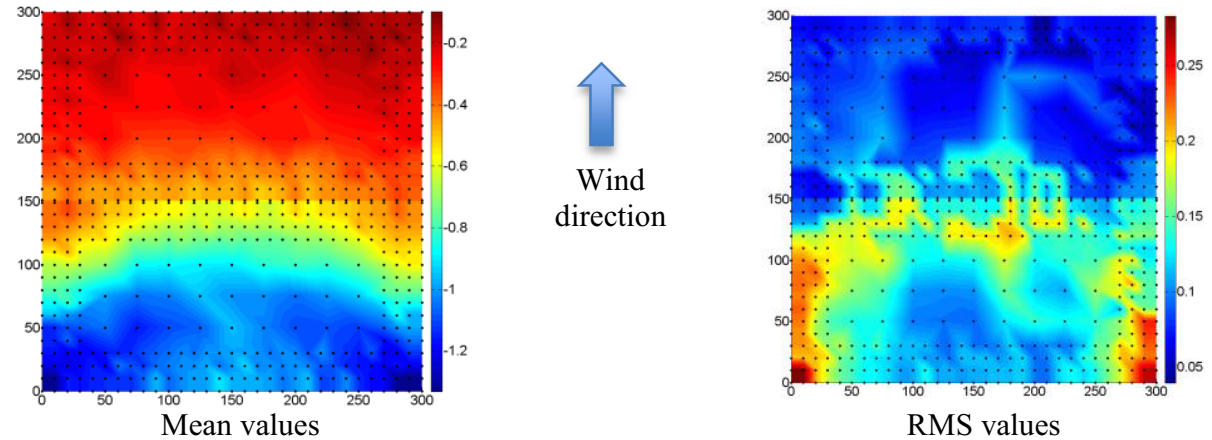

Fig. 6. Pressure coefficients for the roof with $\alpha=5^{\circ}$ in case of smooth flow and wind angle $\theta=0^{\circ}$.
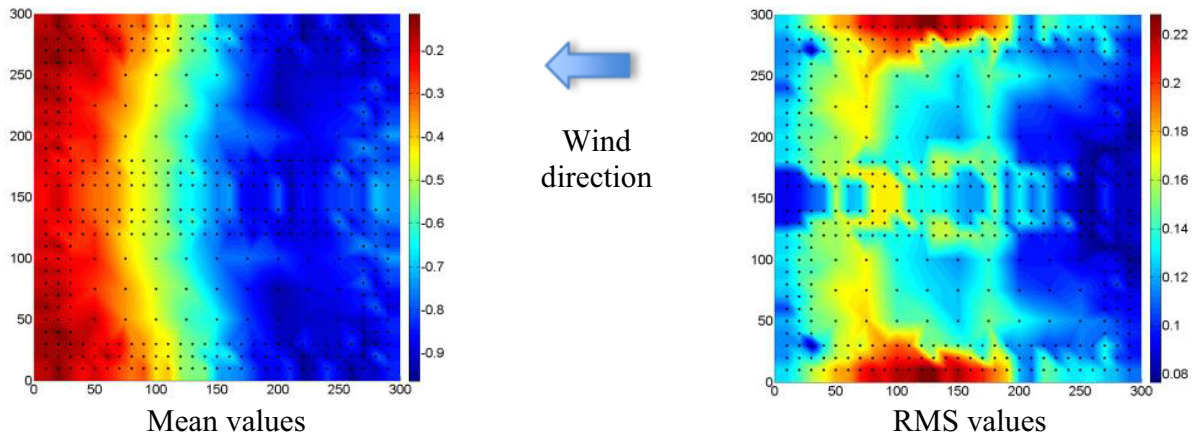

Fig. 7. Pressurs coefficients for the with $\alpha=5^{\circ}$ in case of smooth flow and wind angle $\theta=90^{\circ}$.
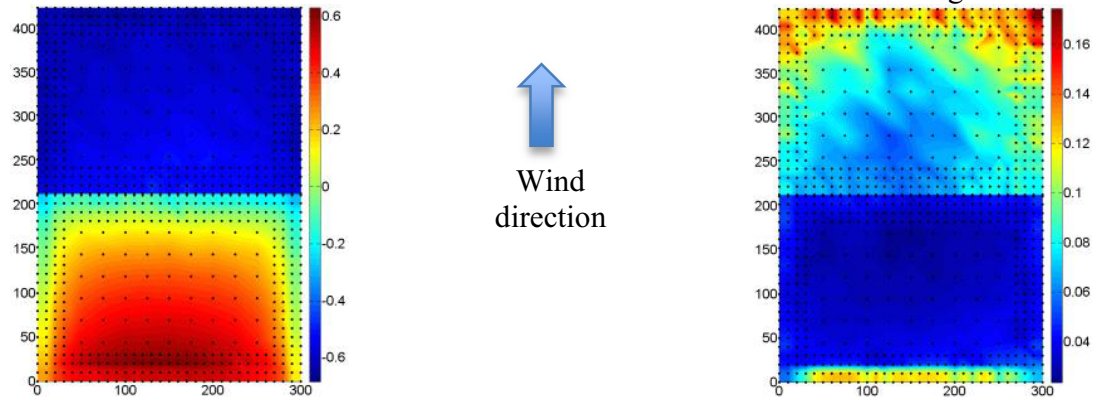

Mean values

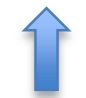

Wind direction

RMS values

Fig. 8. Pressure coefficients for the with $\mathrm{h} \alpha=45^{\circ}$ in case of smooth flow and wind angle $\theta=0^{\circ}$.
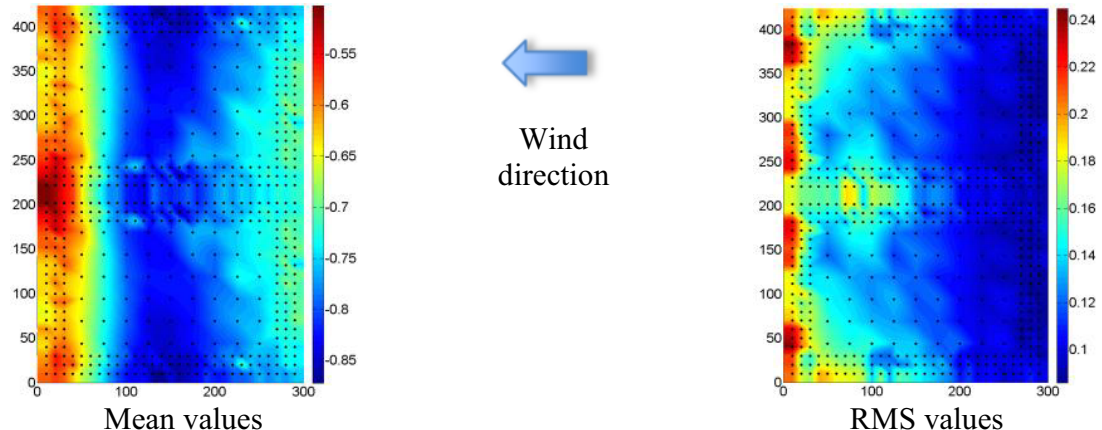

Fig. 9. Pressure coefficients for the with $\alpha=45^{\circ}$ in case of smooth flow and wind angle $\theta=90^{\circ}$. 

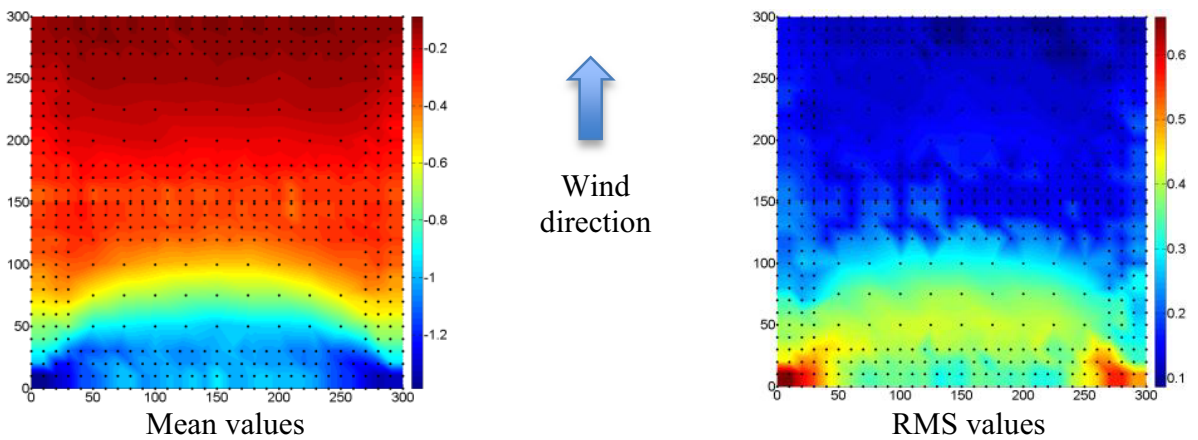

Fig. 10. Pressure coefficients for the roof with $\alpha=5^{\circ}$ in case of turbulent flow and wind angle $\theta=0^{\circ}$.
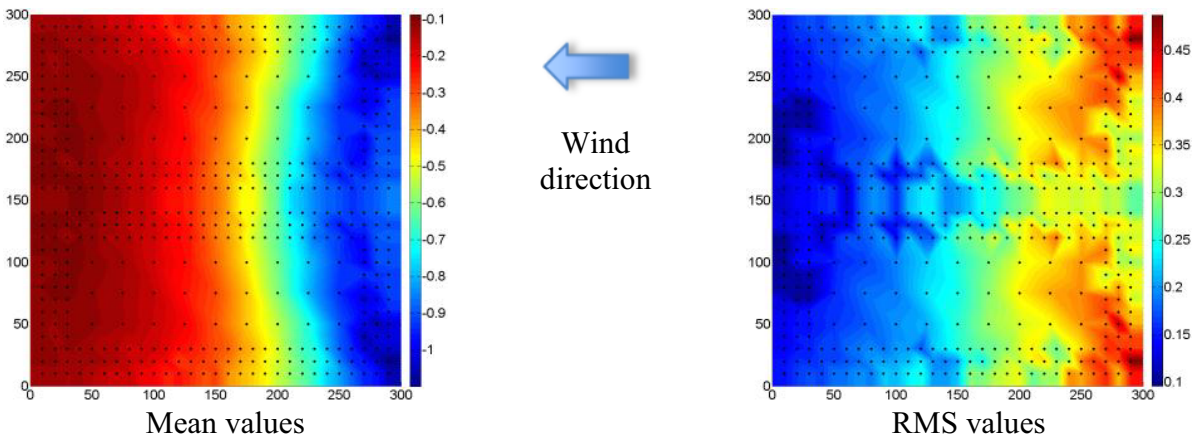

Fig. 11. Pressure coefficients for the roof with $\alpha=5^{\circ}$ in case of turbulent flow and wind angle $\theta=90^{\circ}$.
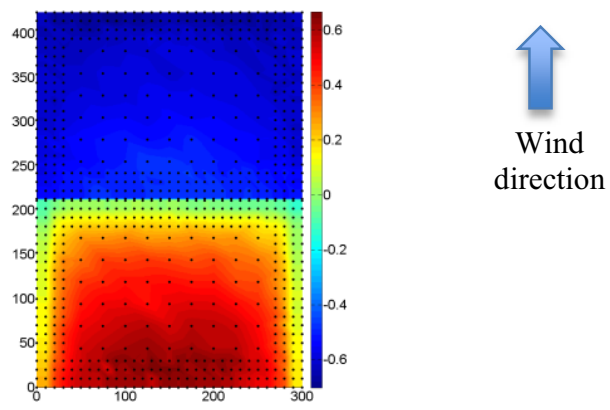

Mean values

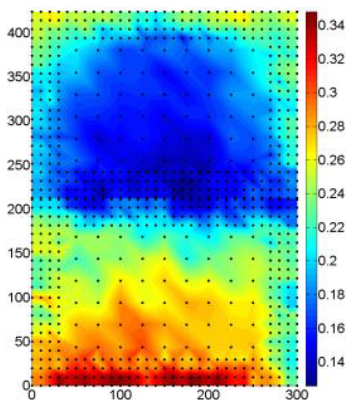

RMS values

Fig. 12. Pressure coefficients for the roof with $\alpha=45^{\circ}$ in case of turbulent flow and wind angle $\theta=0^{\circ}$.
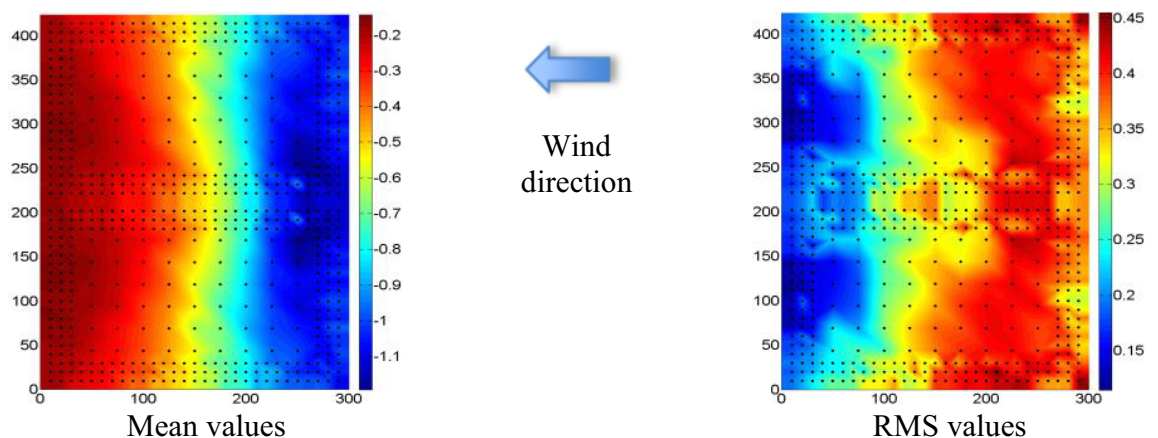

Fig. 13. Pressure coefficients for the roof with $\alpha=45^{\circ}$ in case of turbulent flow and incidence angle $\theta=90^{\circ}$. 
Table 1. Measured local pressure coefficients for the gable with roof inclination $\alpha=5^{\circ}$.

\begin{tabular}{|c|c|c|c|c|c|c|c|c|c|c|c|}
\hline \multirow{2}{*}{$\theta$} & \multirow{2}{*}{ Zone } & \multicolumn{2}{|c|}{ Code } & \multicolumn{4}{|c|}{ Smooth flow } & \multicolumn{4}{|c|}{ Turbulent flow } \\
\hline & & $\mathrm{C}_{\mathrm{pENV}}$ & $\mathrm{C}_{\mathrm{p} C \check{S N}}$ & $\mathrm{C}_{\mathrm{p}}$ & $\sigma_{\mathrm{Cp}}$ & $C_{p}-\sigma_{C p}$ & $\mathrm{C}_{\mathrm{p}}+\sigma_{\mathrm{Cp}}$ & $\mathrm{C}_{\mathrm{p}}$ & $\sigma_{\mathrm{Cp}}$ & $\mathrm{C}_{\mathrm{p}}-\sigma_{\mathrm{Cp}}$ & $\mathrm{C}_{\mathrm{p}}+\sigma_{\mathrm{Cp}}$ \\
\hline \multirow{5}{*}{$0^{\circ}$} & $\mathrm{F}$ & -1.70 & -0.55 & -1.16 & 0.16 & -1.32 & -1.00 & -1.12 & 0.44 & -1.56 & -0.68 \\
\hline & G & -1.20 & -0.55 & -1.02 & 0.11 & -1.13 & -0.91 & -1.03 & 0.36 & -1.39 & -0.67 \\
\hline & $\mathrm{H}$ & -0.60 & -0.55 & -0.86 & 0.15 & -1.01 & -0.71 & -0.60 & 0.31 & -0.91 & -0.29 \\
\hline & $\mathrm{J}$ & -0.60 & -0.40 & -0.41 & 0.11 & -0.52 & -0.30 & -0.30 & 0.16 & -0.46 & -0.14 \\
\hline & I & -0.60 & -0.40 & -0.25 & 0.08 & -0.33 & -0.17 & -0.18 & 0.14 & -0.32 & -0.04 \\
\hline \multirow{4}{*}{$90^{\circ}$} & $\mathrm{F}$ & -1.60 & -0.70 & -0.87 & 0.11 & -0.98 & -0.76 & -1.01 & 0.40 & -1.41 & -0.61 \\
\hline & G & -1.30 & -0.70 & -0.80 & 0.09 & -0.89 & -0.71 & -0.92 & 0.33 & -1.25 & -0.59 \\
\hline & $\mathrm{H}$ & -0.70 & -0.70 & -0.85 & 0.12 & -0.97 & -0.73 & -0.65 & 0.32 & -0.97 & -0.33 \\
\hline & I & -0.60 & -0.50 & -0.40 & 0.15 & -0.55 & -0.25 & -0.17 & 0.18 & -0.35 & 0.01 \\
\hline
\end{tabular}

Table 2. Measured local pressure coefficients for the gable with roof inclination $\alpha=45^{\circ}$.

\begin{tabular}{|c|c|c|c|c|c|c|c|c|c|c|c|}
\hline \multirow{2}{*}{$\theta$} & \multirow{2}{*}{ Zone } & \multicolumn{2}{|c|}{ Code } & \multicolumn{4}{|c|}{ Smooth flow } & \multicolumn{4}{|c|}{ Turbulent flow } \\
\hline & & $\mathrm{C}_{\mathrm{pENV}}$ & $\mathrm{C}_{\mathrm{pČSN}}$ & $\mathrm{C}_{\mathrm{p}}$ & $\sigma_{\mathrm{Cp}}$ & $\mathrm{C}_{\mathrm{p}}-\sigma_{\mathrm{Cp}}$ & $\mathrm{C}_{\mathrm{p}}+\sigma_{\mathrm{Cp}}$ & $\mathrm{C}_{\mathrm{p}}$ & $\sigma_{\mathrm{Cp}}$ & $\mathrm{C}_{\mathrm{p}}-\sigma_{\mathrm{Cp}}$ & $\mathrm{C}_{\mathrm{p}}+\sigma_{\mathrm{Cp}}$ \\
\hline \multirow{5}{*}{$0^{\circ}$} & $\mathrm{F}$ & +0.70 & 0.30 & 0.43 & 0.06 & 0.37 & 0.49 & 0.48 & 0.29 & 0.19 & 0.77 \\
\hline & G & +0.70 & 0.30 & 0.57 & 0.06 & 0.51 & 0.63 & 0.62 & 0.30 & 0.32 & 0.92 \\
\hline & $\mathrm{H}$ & +0.60 & 0.30 & 0.26 & 0.03 & 0.23 & 0.29 & 0.37 & 0.25 & 0.12 & 0.62 \\
\hline & $\mathrm{J}$ & -0.30 & -0.40 & -0.54 & 0.07 & -0.61 & -0.47 & -0.50 & 0.15 & -0.65 & -0.35 \\
\hline & I & -0.20 & -0.40 & -0.59 & 0.09 & -0.68 & -0.50 & -0.58 & 0.18 & -0.76 & -0.40 \\
\hline \multirow{4}{*}{$90^{\circ}$} & $\mathrm{F}$ & -1.10 & -0.70 & -0.73 & 0.09 & -0.82 & -0.64 & -1.04 & 0.38 & -1.42 & -0.66 \\
\hline & G & -1.40 & -0.70 & -0.71 & 0.09 & -0.80 & -0.62 & -1.09 & 0.36 & -1.45 & -0.73 \\
\hline & $\mathrm{H}$ & -0.90 & -0.70 & -0.78 & 0.11 & -0.89 & -0.67 & -0.87 & 0.39 & -1.26 & -0.48 \\
\hline & I & -0.50 & -0.50 & -0.73 & 0.15 & -0.88 & -0.58 & -0.29 & 0.25 & -0.54 & -0.04 \\
\hline
\end{tabular}

The values of coefficients from Eurocode reflect the measurement with higher accuracy in most of the zones compared to former Czechoslovak code. This applies particularly for the windward side of the roof and mainly the zones F, G. The mean values for both types of flow do not differ much in most cases. Turbulence affects the RMS values of the pressures in both cases of the roof inclination. However, it is more significant for roof inclination $\alpha=45^{\circ}$.

\section{Conclusions}

The measurements of wind pressure coefficients at two gable roofs with different inclination were carried out in a wind tunnel. The results are presented in terms of the pressure maps in order to compare the results with the design codes where the roof is divided into several areas of exposition. The model has been placed in a smooth airflow, as well as into the turbulent one, which was used to model the atmospheric boundary layer above the urban terrain (category IV). Measurements were performed at Reynolds numbers that are already typical of the actual flow, so that the results are not affected by the nature of the flow. 
The data of this study has been developed with sufficient versatility to allow comparison of wind load provisions of codes related to gable roofs with two different slopes. It provides instantaneous detailed pressure patterns over entire roof area. By comparison with the codes it can be concluded at first that the high tap areal density in the aerodynamically important zones may improve the capture of large suction loads or other important phenomena. Also, it turns out that there is still relatively high difference between the respective codes [10] and [11] in some zones. This discrepancy naturally reflects the historical contents and development of both codes. In the most cases Eurocode [10] gives more accurate results than [11], especially for the chosen methodology. This goes in hand with the probabilistic approach applied in recent wind engineering science.

It is our perspective to analyse the data with respect of its statistical parameters. The influence of other direction on the coefficients and deviation of the pressure coefficients from their coded values is envisaged too.

This research was financially supported by the project GAČR No. 17-26353J of the Czech Science Foundation and CET sustainability project LO12 (SaDeCET) of the Ministry of Education Youth and Sport of the Czech Republic.

\section{References}

1. J. D. Holmes, Journal of Wind Engineering and Industrial Aerodynamics 53, 105-123, (1994)

2. M. Kanda, E. Maruta, Journal of Wind Engineering and Industrial Aerodynamics 50, 173-182, (1993)

3. D. Meecham, D. Surry, A. G. Davenport, Journal of Wind Engineering and Industrial Aerodynamics 38, 257-272, (1991)

4. P. C. Case, N. Isyumov, Journal of Wind Engineering and Industrial Aerodynamics 7778,107-118, (1998)

5. X. Jing, Y. Li, The Scientific World Journal 2013, 11 pages, (2013).

6. C.P.W. Geurts, Journal of Wind Engineering and Industrial Aerodynamics 64, 89-100, (1996)

7. C. Guerts, P. Blackmore, S.O Hansen, M. Hortmanns, G.,Sedlacek, P. Spehl, P. Staalduinen, B. Zimmerli. Proceedings 3rd European \& AfricanConference on Wind Engineering, 165-172, (2001)

8. C. Geurts, C. van Bentum, Wind Effects on Buildings and Design of Wind-Sensitive Structures, 31-65, (2007)

9. M. Kasperski, C. Geurts, A. Goliger, Wind and Struct., An Int. J. 8 (4), 295-307, (2005)

10. ČSN EN 1991-1-4, Zatižení konstrukcí - Část 1-4: Obecná zatíženi-Zatižení větrem

11. ČSN 73 0035, Zatiženi stavebnich konstrukci

12. R. Meroney, Report University of Karlsruhe (1986)

13. ASCE: Wind Tunnel Studies of Buildings and Structures, Manual of practice no. 67, (1999) 